\title{
Nerve Growth Factor(s) Mediated Hypothalamic Pituitary Axis Activation Model in Stress Induced Genesis of Psychiatric Disorders
}

Ashutosh Kumar*1,6, Pavan Kumar ${ }^{1,6}$, Vikas Pareek ${ }^{2,6}$, Muneeb A. Faiq ${ }^{3,6}$, Khursheed Raza ${ }^{1,6}$, Pranav Prasoon ${ }^{4,6}$, Sankat Mochan ${ }^{1,6}$, Vivek Sharma ${ }^{5,6}$

1. Department of Anatomy, All India Institute of Medical Sciences (AIIMS). New Delhi, India

2. Computational Neuroscience and Neuroimaging Division, National Brain Research Centre (NBRC), Manesar, Haryana, India

3. Department of Ophthalmology, All India Institute of Medical Sciences (AIIMS). New Delhi, India.

4. Spinal Cord and Brain Injury Research center, Department of Physiology, University of Kentucky, Lexington, KY, USA

5. Department of Physiology, Jawaharlal Institute of Postgraduate Medical Education and Research (JIPMER), Puducherry, India

6. Etiologically Elusive Disorders Research Network (EEDRN)

*Corresponding author

Email- aiims.ashu@gmail.com 


\begin{abstract}
Apart from their established role in embryonic development Nerve Growth Factors (NGFs) have diverse functions in the nervous system. Their role in integration of physiological functioning of the nervous system is now attracting attention. In the present analysis, we propose a new paradigm about a novel role of NGFs. We hypothesize that NGFs play imperative role in maintaining psychological integrity of an individual as a biological system. This function may be mediated through HPA-axis- operated homeostatic mechanisms; stress induced disruption of which may lead to psychiatric disorders.
\end{abstract}

Current literature suggests existence of constitutive homeostatic regulatory mechanisms for NGFs disruption which may lead to important behavioural effects. NGFs have been shown to play crucial parts in endocrine regulation. This is especially true with the prototype 'NGF' and Brain Derived Neurotrophic Factor (BDNF). These moieties have been observed to play important role in maintaining neuro-endocrine homeostasis thereby having a profound impact on the psychological health of an individual. Role of NGFs and HPA-axis activation (in separate studies) in developing psychiatric disorders - especially those born of stress - have been established. Literature suggests their unique interplay for producing a common effect which might be implicated in stress induced genesis of psychiatric disorders. This aspect, therefore, needs to be elucidated further as a disease etiogenesis model. This model may yield important insights into the evolution of psychiatric disorders and may open ways for new therapeutic approaches.

Key words: HPA axis; NGFs; psychiatric disorders; prevention of mental diseases; stress 


\section{GRAPHICAL ABSTRACT}

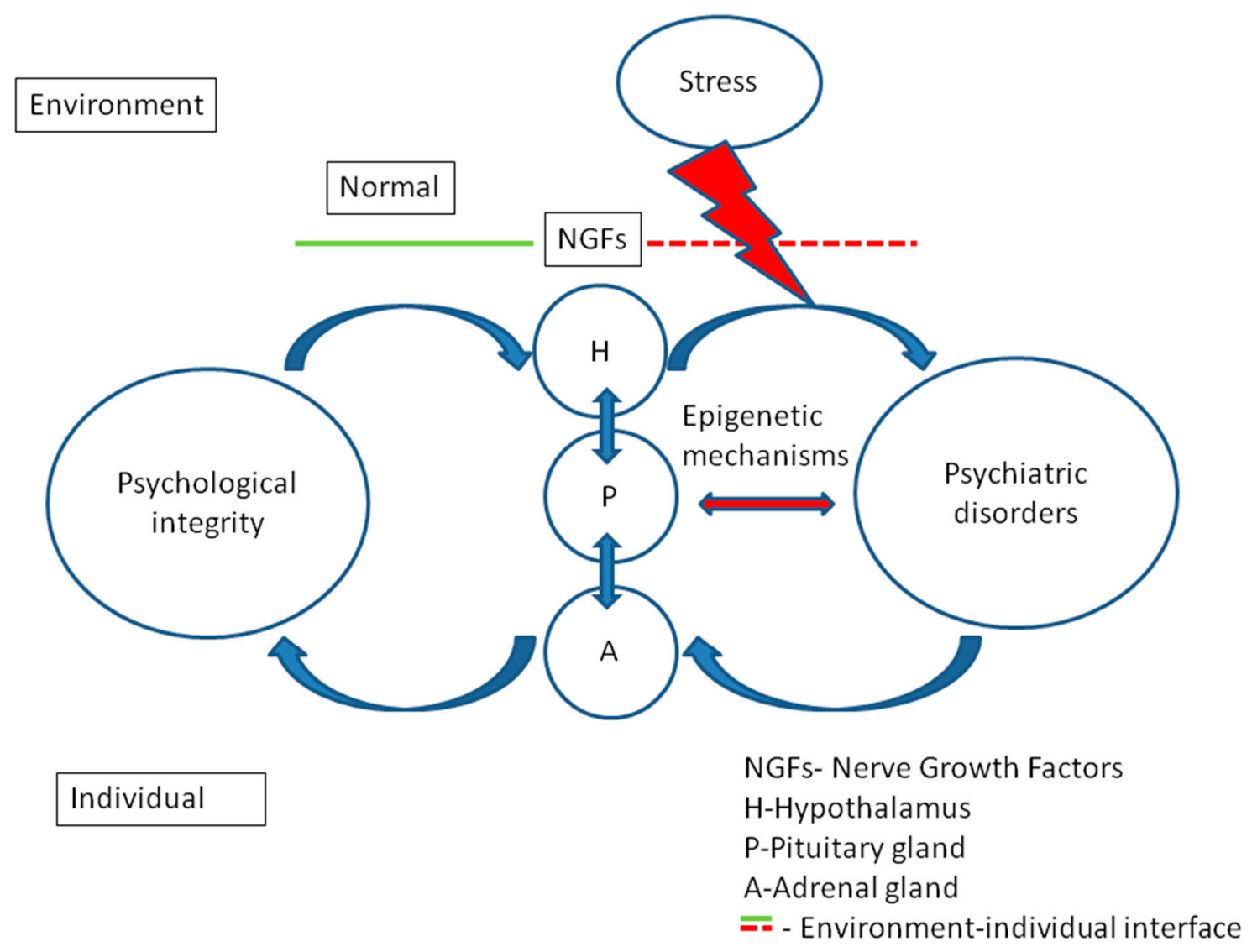

\section{INTRODUCTION}

The emerging role of Nerve Growth Factors (NGFs) in integration of physiological functioning of the nervous system is gaining a lot of interest. NGFs, especially the prototype 
'NGF' and Brain Derived Neurotrophic Factor (BDNF) have been stated to have important roles in maintaining neuro-endocrine homeostatic status of the body, which could have a great impact on the psychological health of individuals (1-3). Hypothalamo-pituitary-adrenal (HPA) axis is understood as the nodal point around which neuro-endocrine-homeostasis of the body is established. In this context, NGFs have been reported effectively for their linkage to genesis of psychiatric disorders; and there are some studies available on the overlapping/crosstalk of NGFs-HPA interactions. We initiated our probes with extensive review of the literature on NGFs' conglomeration in stress, and its causal relationship to psychiatric disorders. Our analysis revealed that a neuro-endocrine model of NGFs-mediated HPA-axis activation may be involved in stress induced genesis of conditions falling within the umbrella of psychiatric disorders.

\section{NGFs: Descendents of Superfamily of Neurotrophin}

NGFs belong to the Superfamily 'Neurotrophins' which has 'NGF' as the prototype, and it also includes BDNF, NT-3, NT-4/5 (4), NT-6 and NT-7 $(5,6)$ (in invertebrates only) (Fig. 1a); which are more or less similar (7) in structure and function to the prototype $\operatorname{NGF}(8,9)$. NGFs execute their actions binding low affinity ${ }^{\mathrm{p} 75}$ neurotrophin receptor $\left({ }^{\mathrm{p} 75} \mathrm{NTR}\right)$ and high affinity Trk receptors (Trk A, B, and C) (9, 10). The NGFs receptor binding has been redundant and one type of receptor can bind to more than one NGFs with differential affinity and known to synergise for the common neural functions $(11,12)$ (Fig. 1b). NGFs secretion in neurons has been found autocrine/paracrine and to perpetuate itself and each other's secretion $(13,14)$. The NGFs and their receptors are regarded as a convergence point for many signalling pathways related to neurocognitive functions (15) and a vast range of effects executed by NGFs in CNS, beginning from normal neuro-physiological functioning to survival and death of neurons (16-18). In adult human brain mainly prototype NGF and BDNF (more specifically BDNF) have been implicated in most of the neurotrophin mediated neurocognitive functions $(19,20)$ although NT-3 and NT-4/5 have been also known to be involved in certain functions related to synaptic plasticity in adult brain (21-23). 

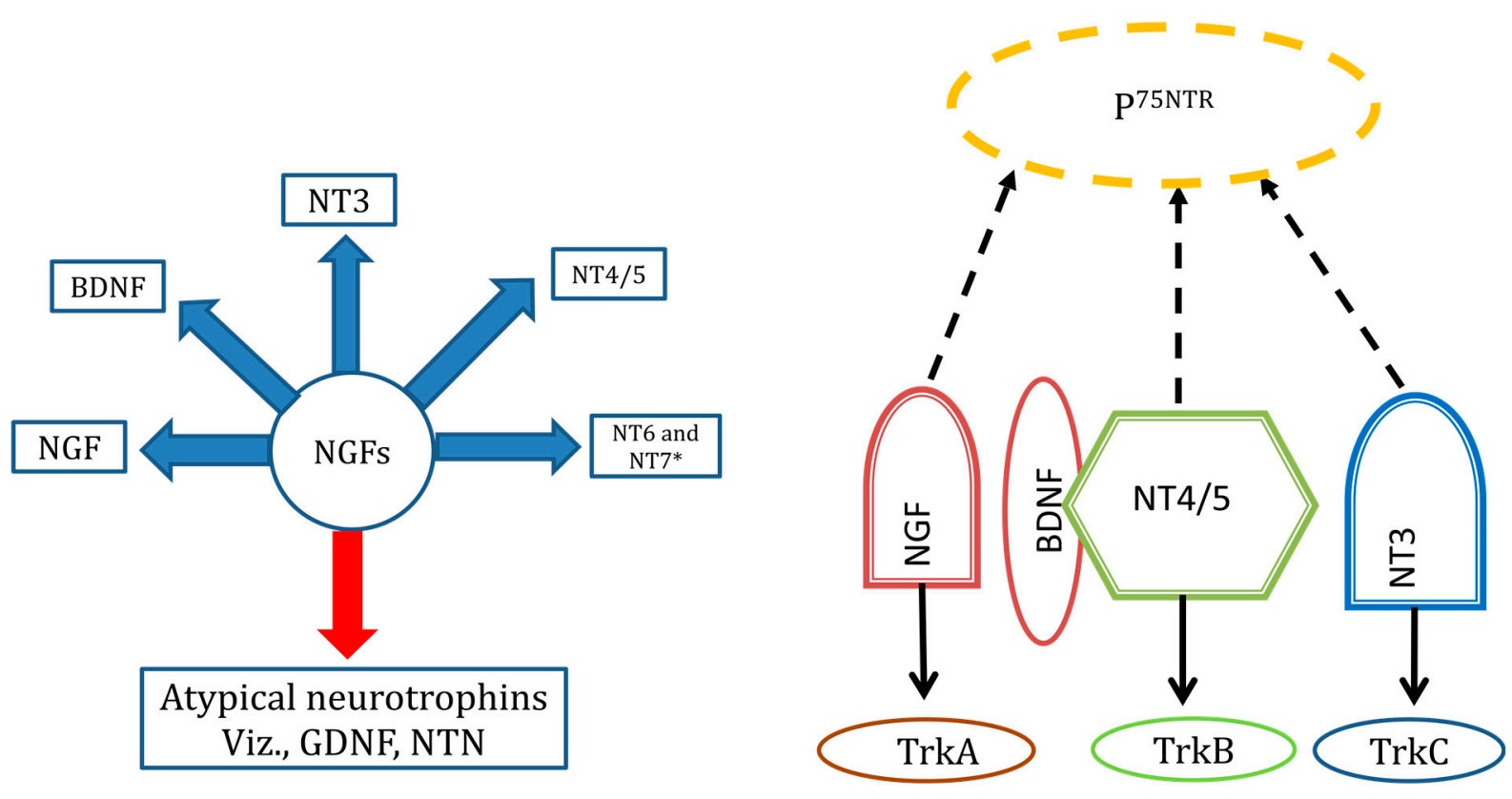

Fig. 1 a. Superfamily of neurotrophins.

NGFs- Nerve growth factors, $*=$ In invertebrates only

\section{b. Nerve growth factors and their cognate receptors.}

(Intact and dashed lines are showing signaling through specific high affinity Trk receptors and a common low affinity receptor- $\mathrm{P}^{75 \mathrm{NTR}}$ respectively.)

NGFs in adult brain: The omnipresent molecules

NGFs and their receptors have been detected ubiquitously in all regions of adult brain in various animal studies, and more specifically in hippocampus and neocortex (24-26). The hippocampus had been noted to have highest NGFs synthesis in brain and amongst all NGFs, BDNF was most abundant (25). The expressions of the NGFs were found heterogeneous and showed region specific dominance in different brain regions. In cortex, a study reported that in rat brain, expression of prototype 'NGF', BDNF, and NT-3 was varying in different layers (26). 
In hippocampus NGFs were present more specifically in pyramidal and granular layer neurons and showed variations in expression in different CA regions, and in cerebellum were more specifically localised to Purkinje and granule cell neurons (27).

Similar to the NGFs, their receptors were also found heterogeneously distributed and showed regions specific dominancy which indicated target regions of their ligands, i.e., TrkB, receptor for BDNF, was found more expressed in ependyma and periventricular brain parenchyma. And TrkA, high affinity receptor for prototype 'NGF' was more densely expressed in basal forebrain regions and striatum (28).

Uniquely, intraventricular injections of NGFs in animal brains showed that they can also diffuse to other brain regions with differential limits i.e., prototype 'NGF' reached to the cortical regions, BDNF limited to the periventricular regions, and NT-3 reached some intermediate destinations (28).

The mode of NGFs secretion in neurons has been a matter of contention. Current evidence suggests, NGFs' secretion is not only constitutional (target derived and showing retrograde axonal transport serving trophic functions in neurons) but also have prominent activity dependent, regulated secretion which move anterograde via dendrites and axons to act at the synapses with similar processes of other neurons; where they add extensively in synaptic transmission and plasticity (29-32).

The prototype NGF was found more specifically expressed in inhibitory GABAergic neurons (co-labelled GAD65/67) than excitatory neurons (co-labelled CaMKIIa). GABAergic neurons are considered as primary source of prototype 'NGF' production in CNS (33).

The expression of NGFs and their receptors were found in different subcortical regions (as striatum, thalamus, hypothalamus, basal forebrain nuclei, septal regions) and brainstem nuclei also. However, the expression was not only restricted in neurons, concomitantly expressed in glial cells and nerve fiber bundles also $(27,28,34)$.

\section{NGFs homeostasis: as a concept}

NGFs have been demonstrated to have extensive role in physiological homeostasis regulation $(3,35,36)$ and it seems reasonable to speculate for a homeostatic control system of their own (3), disruption of which may result in psychiatric disorders $(37,38)$. Evolutionary link therefore has been seen amongst different NGFs by sharing common moiety, receptors, signalling cascades and mode of action (10). 
The neurons found to co-localize more than one NGFs or their receptors (39). The NGFs have also noticed to regulate own or other family members in autocrine/paracrine manner in CNS (14), and their regulation also found to follow circadian rhythm (40, 41). And a change in NGFs levels also found to reflect on levels of HPA hormones or various neurotransmitters in the brain $(42,43)$. NGFs also found to show neural activity dependent secretion, change in levels with sleep, physical activities, and responsive to the environmental changes (44-46). All these evidences suggest that NGFs maintain a homeostatic control system of their own which plays in concert with other neuro-endocrine homeostatic systems in the body.

\section{Role of NGFs in maintenance of normal behaviour}

The significant role of NGFs in normal behavioural processes has been warranted by peer reviewed research $(47,48)$. The role of NGFs in various neurophysiological functions which determine normal behavior is known for long; the specific NGFs have been found involved in synaptic transmission $(20,49)$, memory and learning (50-52), sleep (53-55), and neuronal protection $(18,56)$.

NGFs have been reported mediating behaviour induced cerebral plasticity $(19,20)$. A forebrain specific BDNF gene knock-out study in adult mice revealed that there was significant (30\% reduction) changes in density of dendritic spines of cortical neurons that reflected in smaller brain size and compromised behaviour as difficulty in spatial learning and greater inclination for depression (48).

A study on male hamsters has shown that differential action of BDNF was responsible for dominant-subordinate relationship in a resident-intruder model in which individual hamsters were identified as winner or loser on the basis of behaviour. Losing animals had significantly more BDNF m-RNA in basolateral and medial nuclei of amygdala while winners had more BDNF m-RNA in dentate gyrus of dorsal hippocampus indicating a role of BDNF in subsequent experience dependent behavioral plasticity. The experience dependent learning of dominant or subordinate behaviour was mediated by BDNF got further confirmed when investigators were able to block acquisition of such behaviour with use of K252a (a Trk receptor antagonist (57).

Single nucleotide polymorphic variants of BDNF (rs6265, Val66Met) and NGF (rs6330, Ala35Val) genes have been reported to be associated with anxiety phenotypes in human 
populations (58). Another study implicated BDNF in depression related personality traits in healthy volunteers (59).

Egan et al found a polymorphic variant of BDNF (Val66Met) in subjects associated with poor episodic memory and abnormal hippocampal activation (60). Few other studies had additionally found the BDNF (Val66Met) polymorph to be associated with anxiety trait, depression, HPA and SAM (sympathetic adrenal medullary) axis hyperactivity, and higher anticipatory cortisol response to psychological stress in population (61-63).

NGFs have also been implicated in various causes of psychosocial stress which may cause deviation from normal social behavior as: social displacement, disharmony, future uncertainty bereavement, complicated upbringing and intense conflicts, etc (64-66).

NGFs have also been implicated in regulation of reproductive behaviours through hypothalamus-pituitary-gonadal (HPG) axis, a close functionary of the HPA. An experimental study claimed that the prototype 'NGF' is the constitutive element of semen and prostatic secretions, and it can mediate influence of male on sexual behaviour of female or can induce ovulations through HPG axis (67).

The prototype 'NGF' has been observed to be associated with intimate sexual behaviours; a study found serum prototype 'NGF' level, and not other NGFs higher in persons indulged in early romantic love (68).

NGFs have a definite role in neurogenesis, network organizations, formation and remodelling of synapses in developing brain which also keeps refining afterwards under their regulation (43). In adult brain (also in humans) where neurogenesis keeps going on as a physiological event; as in hippocampal region (dentate gyrus) and subventricular zone (SVZ) of lateral ventricles $(69,70)$; the role of NGFs in induced neurogenesis, remodelling of neuronal connections, and synaptic organizations with new experiences in these brain regions provide individual the ability to adapt to new life situations $(71,72)$, a disruption of which may lead to aberrant behavioural changes alternatively described as psychiatric disorders (73).

NGFs have also been seen to interact with dopaminergic neurons thus facilitating dopamine release at synapses $(74,75)$. Dopamine is the chief substrate for mesolimbic reward pathway. Such a function is crucial for experience dependent modulation of normal behaviour (76). A 
dopamine-BDNF link in reward pathway functions has been well substantiated by animal model studies of social defeat stress $(77,78)$.

Neuronal activity dependent secretions of NGFs have been shown to involve cAMP response element binding protein (CREB) as the chief mediator. CREB is known to mediate many neurotransmitters and neuromodulators in brain. It also activates many transcription factors, and influences expression of immediate early genes involved in synaptic transmission and plasticity, and experience dependent remodelling of neuronal circuits (79-81). The extensive role of CREB in normal neuronal functions and resultant behaviour, and its NGFs mediated regulation further substantiates that NGFs may be crucial for maintenance of normal mental health and behaviour.

\section{NGFs present a common link to the psychiatric disorders}

NGFs have been implicated in almost all kinds of psychiatric disorders. There is ample evidence for involvement of prototype NGF and BDNF in development of schizophrenia (82-84), bipolar illness $(37,85)$, depression $(86,87)$, Obsessive-compulsive disorder (OCD) (88-90), post traumatic stress disorder (PTSD) (91, 92), eating disorder (93), conversion disorder (94), and also in anxiety and aggression $(57,83,95)$ and social defeat induced avoidance behaviour (77). Many studies reported NGFs' involvement in psychopathology of suicidal behaviour (96-98). The prototype 'NGF' has been implicated in the mechanism of drug addiction, alcoholism and substance abuse also (99-102). The published reports suggest that an imbalance in NGFs homeostasis may have significant contribution in the pathogenesis of these behavioural deviances $(1,37,103)$; even from the treatment point of view, the antidepressant effects of antipsychotic drugs are known to mediate through NGFs $(2,38)$.

\section{Plausible mechanisms for NGFs mediated HPA axis activation model}

Increasing number of studies is linking neurotrophins or NGFs, and stress to the pathophysiology of psychiatric disorders (104-106). NGFs work as a homeostatic interface between organism and environment which is robust to get disrupted from ordinary perturbations of daily life and helps the organism to adapt to the changing survival conditions 
(107). A persistent state of mounting stress may disrupt NGFs homeostasis in the body (107, $108)$, and in consequence may dysregulate NGFs mediated HPA axis activation $(107,109)$. The ambiguity raised in the NGFs-HPA axis regulatory system is to negatively affect mood and cognition of the individual which in turn would cause more NGFs-HPA axis dysregulation, and a vicious cycle of this (Fig. 2) may lead to stable changes in individual's behaviour in an attempt to re-establish the disrupted homeostasis (110-112). If the NGFsHPA axis homeostasis is not re-established, the deviant changes in behaviour may further progress into manifested psychiatric disorders $(19,113)$.

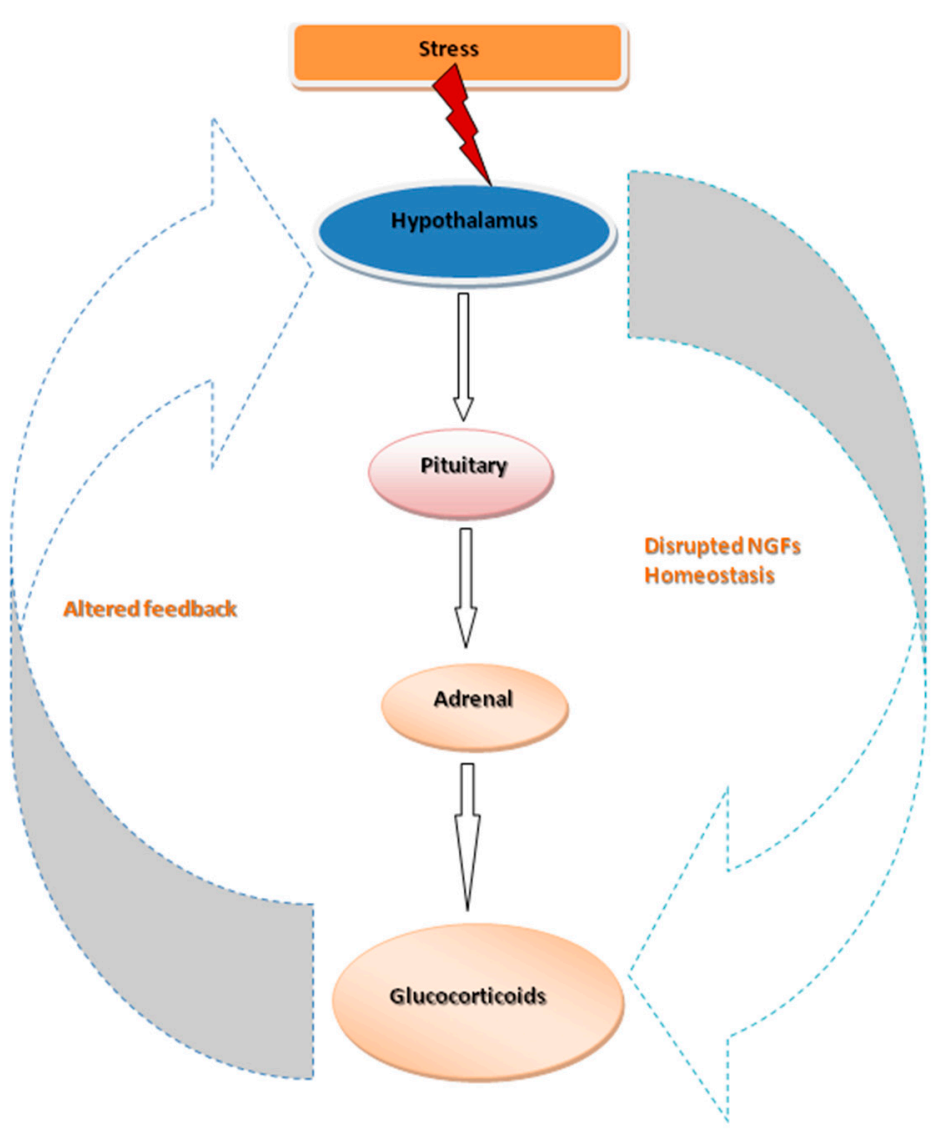

Fig. 2. Stress induced HPA axis mediated disruption in NGFs homeostasis 
Published literature supports the notion that stress induced NGFs mediated dysregulation of HPA axis may end up as a psychiatric disorder (if stress causing factors persist). NGFs show activity and stress based synthesis in various brain regions involved in stress response regulation $(1,105,114)$ and the involved brain regions are known to differentially regulate HPA axis. For example, prefrontal cortex and hippocampus are known to inhibit but amygdala excites it (115). In the similar context, chronic immobilization stress in male rats was observed to produce inverse neuronal BDNF secretion and hence growth changes mediated by it, in hippocampus and amygdala (116).

The differential regulation of HPA axis by the various brain regions involved in stress response regulation perhaps may be the reason of phenotypic diversity observed in psychiatric disorders $(115,117)$.

Experimental studies suggest that hippocampus is the most severely affected brain region (owing to prolonged glucocorticoid secretion) in chronic restraint stress (118-120). Hippocampal inhibitory control of HPA axis activity, which is a normal phenomenon in homeostasis, is also known to be compromised in chronic restraint stress $(115,121)$; and along with glucocorticoids, NGFs are known to be central players causing this dysregulation $(109,112,122)$. Hippocampal pyramidal neurons secrete NGFs in response to stress which correspond to HPA axis activity $(123,124)$, and also TrkB, the receptor for BDNF is found to be co-localized with glucocorticoid receptor (GR) and having mutual influence on each other's signalling in these neurons (122). A study by Lambert et al has shown in primary rat cortical neurons that BDNF induces structural change at GR gene (phosphorylation at serine 155 and 287) and causes significant change in its transcriptome (125). Similar evidence for essential glucocorticoid-BDNF interaction for stress response have also been noted in hypothalamus controlling CRH synthesis at PVN (114). A schematic depiction of NGFs mediated hippocampal-HPA axis regulation in normal health and chronic restraint stress is presented in Fig. 3. 


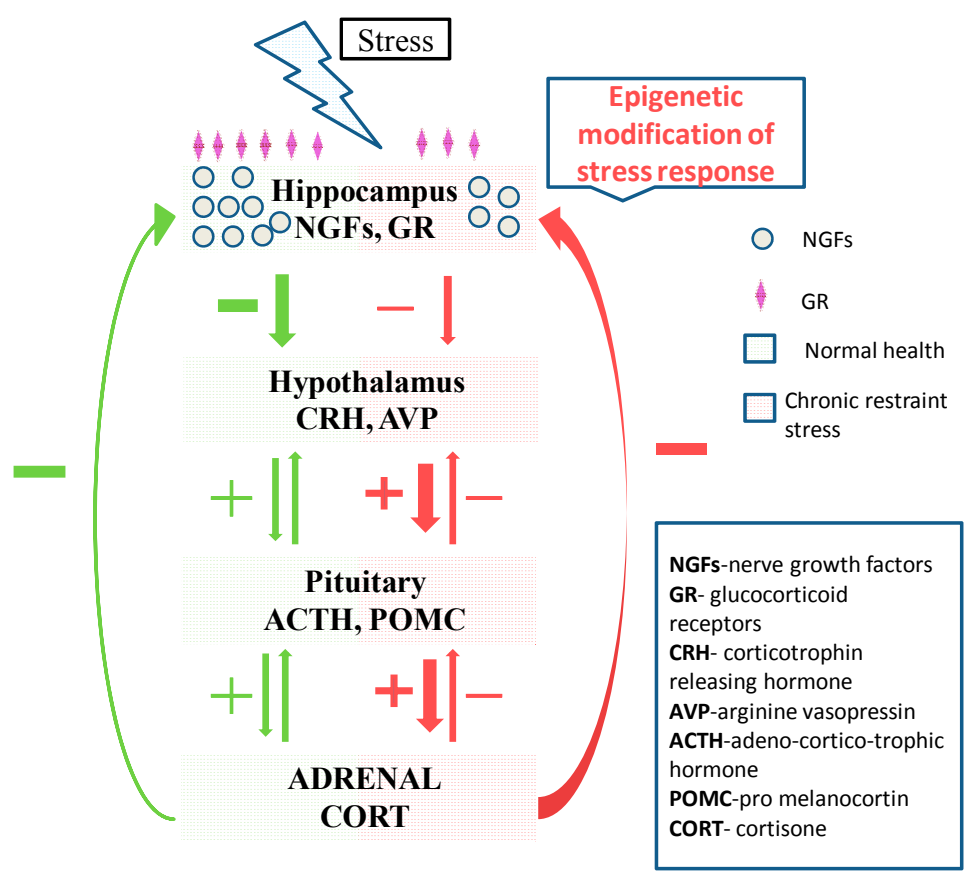

Fig. 3. Hippocampal-HPA axis regulation in normal health and chronic restraint stress

(In normal health: Increased secretion of specific NGFs in hippocampus, and HPA axis hormones occurs in response of fresh stressful stimuli. An increase in cortisone release at adrenal as a stress response sends negative feedback through glucocorticoid receptor (GR) in hippocampus (but GR expression is maintained) which in turn inhibits HPA activity. Also the NGFs secretion response in challenge of fresh stress is maintained. In chronic restraint stress: HPA axis regulation gets epigenetically modified causing enduring increase in cortisone secretion at adrenal which in turn increases feedback inhibition at hippocampus resulting in significant reduction in GR expression, which further decreases hippocampal inhibitory control on HPA axis facilitating its persistent hyperactivation and exaggerated response in challenge of fresh stressful stimuli. The NGFs secretion response is also reduced. (Thickness of signaling lines and feedback loops are indicating their strength) (126). 


\section{Evidences from animal model studies}

There are multiple animal model studies supporting NGFs mediated regulation of HPA axis. Studies have also established dysregulation of particular NGFs (prototype 'NGF' and BDNF) and HPA axis in chronic stress giving way for genesis of psychiatric disorders.

Givalois et al showed that a single intra-cerebroventricular injection of BDNF in nonanaesthetized adult rats modified HPA axis activity. In paraventricular nuclei of hypothalalamus an increase of BDNF was found to alter $\mathrm{CRH}$ (corticotrophin releasing hormone) and AVP (arginine vasopressin) synthesis, which in turn lead ACTH release (adreno-cortico-trophic hormone) from anterior pituitary and cortisone release from adrenal cortex. This change in HPA axis activity in response of exogenous BDNF was similar to the physiological condition when a rat is subjected to immobilization stress which suggested role of BDNF as stress responsive intracellular messenger (127).

Naert et al examined the effect of chronic stress (restraint 3 hour/day for 3 weeks) in adult rats on behaviour and HPA axis activity in parallel with studying BDNF levels in hypothalamus, pituitary and hippocampus. Chronic stress induced anxiety, anhedonia and depression like states in these model animals. HPA axis activity was found highly modified with increase in the basal level of hypothalamic CRH and AVP synthesis and plasma levels of ACTH and cortisone. Added to that, basal BDNF levels were increased in the hypothalamus, pituitary and hippocampus. Also, the BDNF response to subsequently applied acute novel stress was found modified. All these findings indicated plausible role of BDNF in chronic stress induced genesis of psychiatric disorders (42).

In a consecutive study Naert et al tested the effect of continuous intra-cerebroventricular administration of BDNF on HPA axis activity in adult rats and found that it not only modified HPA activity but also biological rhythms. These authors had a view that a change in HPA activity and biological rhythms occurred through regulatory effect of BDNF on AVP mRNA expression (AVP m-RNA was found to be upregulated after continuous BDNF infusion) in suprachiasmatic nucleus ( $\mathrm{SCN}$ ) of hypothalamus (which is regarded as the biological clock) (128). The BDNF and its cognate receptor Trk B are known to be expressed in $\mathrm{SCN}$ and showed circadian variations (41).

Furthermore, in a study Naert et al tested the effect of partial inhibition of endogenous BDNF on HPA activity in adult rats. BDNF knock down by small interfering RNA (siRNA) caused 
decreased endogenous BDNF production in different brain regions which although didn't influence basal HPA activity but the knock down rats showed decreased BDNF production and concomitant altered ACTH and cortisone production in response to restraint stress which indicated essential role of BDNF in stress adaptation (129).

The acute and chronic intra-cerebroventricular administration of BDNF into brain of rat pups found to produce changes in HPA activation but only chronic administration of BDNF caused stable changes in HPA axis regulation resulting in persistently increased secretion of cortisone by adrenal cortex leading to deviant behaviour, while changes in HPA axis activation induced by acute doses of BDNF were adjusted by bodily homeostatic systems $(127,128)$. The HPA axis changes induced by chronic administration of BDNF resembled that by chronic stress and believed to involve epigenetic mechanisms $(130,131)$. The epigenetic mechanisms are supposed to induce structural adaptations in the chromosomal regions so as to register, signal or perpetuate altered activity states (132). The essential role of the epigenetics in producing stable changes in HPA axis regulation has been effectively proved in animal model studies of chronic stress. Maternal separation of the rat pups (which is regarded as an equivalent to chronic stress) induced stable changes in HPA axis regulation leading to hyper-cortisone response in stress challenges. The HPA axis changes were mediated by epigenetic mechanisms in the form of hypermethylation in promoter regions of glucocorticoid receptor (GR) gene hence reducing expression of GR receptors, which in turn promoted cortisone hyper secretion by influencing negative feedback loops (133-135), conversely, better maternal care caused hypomethylation in the promoter region of the GR gene increasing the GR expression leading to reduced cortisone secretion response in face of stress challenges (135).

In experiments blocking the promoter region methylation of GR by histone deacetylase inhibitor (introduces change in chromatin structure which would reduce DNA length available for methyl group attachment) blocked any increase of cortisone secretion in stress challenges in rat pups who had comparatively got low maternal care (135). In contrast, addition of methyl groups (by introducing methyl donors) in promoter regions of GR gene in adult rats which had got good maternal care as pups induced hyper cortisone secretion thus reversing the set maternal programming for stress response (136). The environmental enrichment could also reverse the maternal separation induced stress response modification (137), which is a good indication for plausible reversibility of HPA axis mediated persistent 
stress induced disorders. Epigenetic modification of HPA axis stress response also occurred at higher levels in the axis than GR synthesis at adrenal, and were also mediated through other epigenetic methods than methylation as phosphorylation (125), histone modifications and micro-RNA mediated transcriptional regulations (138).

In an ELS study in male mice maternal separation induced increase in cortisone response in next stress challenges was found associated with sustained hypomethylation in POMC (a precursor for $\mathrm{ACTH}$ ) gene promoter region. The mice also presented despair like behaviour and memory deficit which were supposedly mediated through AVP signalling and epigenetic adaptations at AVP enhancer locus (139). A persistent increase in AVP expression was found in hypothalamic paraventricular nuclei (PVN) associated with decreased DNA methylation at AVP enhancer locus in an another ELS study done in mice (140).

In a different ELS study in adult rats decreased AVP enhancer locus methylation in amygdala found associated with development of active coping mechanisms when presented with predatory stress challenge (141).

Not only the BDNF expression, but also the prototype NGF had been found to be altered significantly in stress caused by various reasons in animal models (123, 142); it was found raised in maternal deprivation in rats (123); and specific hypothalamic nuclei were reported having raised 'NGF' levels in aggression in mice (95). Occasional reports also implicated NT3 in stress (108).

A dopaminergic modulation of NGFs-HPA axis mediated stress response has also been shown in animal models of social defeat. Social defeat was found to raise BDNF levels in nucleus accumbens (NAc) which is a destination centre for dopaminergic neurons residing at ventral tegmental area (VTA) in mesolimbic reward pathway. A raised BDNF level was found associated with learning social avoidance behaviour in model animals and mediated through CRH (from PVN of hypothalamus) $(77,78)$.

\section{Translational studies in human}

There are also reports translating the animal model observation of stress response modifications in persistent stress in human subjects (142-144). A single nucleotide 
polymorphism of BDNF (Val66Met) in human populations has also been found associated with altered stress response (63).

\section{Role of epigenetic modifications in NGFs mediated HPA activation model: Behavioural adaptations to persistent stress manifesting as psychiatric disorders}

NGFs have been intensively implicated in creating epigenetic memory of environmental stimulus $(65,104)$. MeCP2 (methyl-CpG-binding domain 2), a methyl binding domain (MBD) and transcription repressor which is essential for accomplishing gene silencing effect of the methylation needed to dissociate from the BDNF promoter region to reprogram the stress response (145). An increase in BDNF synthesis accompanying any neuronal activity has been a neurophysiological phenomenon. A rapid increase in its synthesis in specific brain regions has been a characteristic finding in face of stress challenges (124, 146); Although methylation in the BDNF promoter (exon IV) in specific brain regions was found in chronic stress only $(42,147)$. The hypermethylation of a CpG nucleotide at 5' end of the binding site of a transcription factor, nerve growth factor inducible protein A (NGFIA) in GR promoter region has also been reported in all rat pups which got reduced maternal care. Certain alteration in the DNA methylation pattern for NGFIA is considered as an essential step in the epigenetic reprogramming of a stress response $(135,148)$.

The persistently raised basal levels of BDNF, and hypercortisone secretion along with other stable alterations in HPA axis set points may be inducing transcriptomic changes in expression of genes related to synaptic functions $(149,150)$, and causing structural and functional changes in neurons in form of the synaptic organization and synaptic transmission leading to altered behaviour of the organism $(20,151)$ which is perceived as a psychiatric disorder. 


\section{CONCLUSIVE REMARKS}

Understanding the mechanisms of NGFs- HPA interactions and its disruption in persistent stress may help to understand stress induced pathogenesis of psychiatric disorders. Experimental proof of emergence and alleviation of psychiatric disorders in loss and gain of NGFs-HPA axis homeostasis in cohort studies can establish the value of this model in general.

\section{CONFLICT OF INTEREST}

Authors declare there are no competing interests

\section{AUTHOR (S) CONTRIBUTIONS}

AK and PK wrote first draft. AK, PK, VP, MA, KR, SM and VS reviewed and edited first draft. MA language edited final draft.

\section{REFERENCES}

1. Alleva E, Francia N (2009): Psychiatric vulnerability: suggestions from animal models and role of neurotrophins. Neurosci Biobehav Rev. 33: 525-536.

2. Duman RS, Monteggia LM (2006): A Neurotrophic Model for Stress-Related Mood Disorders. Biol Psychiatry. 59: 1116-1127.

3. Jackson G, Werrbach-Perez K, Pan Z, Sampath D, Perez-Polo J (1994): Neurotrophin regulation of energy homeostasis in the central nervous system. Dev Neurosci. 16: 285-290.

4. Bartkowska K, Turlejski K, Djavadian RL (2010): Neurotrophins and their receptors in early development of the mammalian nervous system. Acta Neurobiol Exp. 70: 454-467.

5. Götz R, Köster R, Winkler C, Raulf F, Lottspeich F, Schartl M, Thoenen H (1994): Neurotrophin-6 is a new member of the nerve growth factor family. Nature. 372: 266-269.

6. Lai KO, Fu WY, Ip FC, Ip NY (1998): Cloning and expression of a novel neurotrophin, NT-7, from carp. Mol Cell Neurosci. 11: 64-76. 
7. Hallböök F (1999): Evolution of the vertebrate neurotrophin and Trk receptor gene families. Curr Opin Neurobiol. 9: 616-621.

8. Levi-Montalcini R, Skaper SD, Dal Toso R, Petrelli L, Leon A (1996): Nerve growth factor: from neurotrophin to neurokine. Trends Neurosci. 19: 514-520.

9. Meakin SO, Shooter EM (1992): The nerve growth factor family of receptors. Trends Neurosci. 15: 323-331.

10. Ebendal T (1992): Function and evolution in the NGF family and its receptors. $J$ Neurosci Res. 32: 461-470.

11. Hennigan A, O'Callaghan RM, Kelly ÁM (2007): Neurotrophins and their receptors: roles in plasticity, neurodegeneration and neuroprotection. Biochem Soc Trans. 35: 424-427.

12. Teng KK, Hempstead BL (2004): Neurotrophins and their receptors: signaling trios in complex biological systems. Cell Mol Life Sci CMLS. 61: 35-48.

13. Kramer BMR, Cruijsen PMJM, Ouwens DTWM, Coolen MW, Martens GJM, Roubos EW, Jenks BG (2002): Evidence that Brain-Derived Neurotrophic Factor Acts as an Autocrine Factor on Pituitary Melanotrope Cells of Xenopus laevis. Endocrinology. 143: 1337-1345.

14. Krüttgen A, Möller JC, Heymach JV, Shooter EM (1998): Neurotrophins induce release of neurotrophins by the regulated secretory pathway. Proc Natl Acad Sci U S A. 95: 9614-9619.

15. Chao MV (2003): Neurotrophins and their receptors: a convergence point for many signalling pathways. Nat Rev Neurosci. 4: 299-309.

16. Barrett GL, Bartlett PF (1994): The p75 nerve growth factor receptor mediates survival or death depending on the stage of sensory neuron development. Proc Natl Acad Sci. 91: 6501-6505.

17. Harrington AW, Ginty DD (2013): Long-distance retrograde neurotrophic factor signalling in neurons. Nat Rev Neurosci. 14: 177-187.

18. Sofroniew MV, Howe CL, Mobley WC (2001): Nerve growth factor signaling, neuroprotection, and neural repair. Annu Rev Neurosci. 24: 1217-1281.

19. Berry A, Bindocci E, Alleva E (2012): NGF, brain and behavioral plasticity. Neural Plast. 2012.

20. Lu B, Nagappan G, Lu Y (2014): BDNF and synaptic plasticity, cognitive function, and dysfunction. Neurotrophic Factors. Springer, pp 223-250.

21. Kokaia M, Asztely F, Olofsdotter K, Sindreu CB, Kullmann DM, Lindvall O (1998): Endogenous neurotrophin-3 regulates short-term plasticity at lateral perforant path-granule cell synapses. $J$ Neurosci Off J Soc Neurosci. 18: 8730-8739.

22. Shimazu K, Zhao M, Sakata K, Akbarian S, Bates B, Jaenisch R, Lu B (2006): NT-3 facilitates hippocampal plasticity and learning and memory by regulating neurogenesis. Learn Mem. 13: $307-315$.

23. Xie C-W, Sayah D, Chen Q-S, Wei W-Z, Smith D, Liu X (2000): Deficient long-term memory and long-lasting long-term potentiation in mice with a targeted deletion of neurotrophin-4 gene. Proc Natl Acad Sci U S A. 97: 8116-8121. 
24. Anderson KD, Alderson RF, Altar CA, DiStefano PS, Corcoran TL, Lindsay RM, Wiegand SJ (1995): Differential distribution of exogenous BDNF, NGF, and NT-3 in the brain corresponds to the relative abundance and distribution of high-affinity and low-affinity neurotrophin receptors. J Comp Neurol. 357: 296-317.

25. Hofer M, Pagliusi SR, Hohn A, Leibrock J, Barde YA (1990): Regional distribution of brainderived neurotrophic factor mRNA in the adult mouse brain. EMBO J. 9: 2459-2464.

26. Pitts AF, Miller MW (2000): Expression of nerve growth factor, brain-derived neurotrophic factor, and neurotrophin-3 in the somatosensory cortex of the mature rat: coexpression with high-affinity neurotrophin receptors. J Comp Neurol. 418: 241-254.

27. Friedman WJ, Black IB, Kaplan DR (1998): Distribution of the neurotrophins brain-derived neurotrophic factor, neurotrophin-3, and neurotrophin- $4 / 5$ in the postnatal rat brain: an immunocytochemical study. Neuroscience. 84: 101-114.

28. Yan Q, Matheson C, Sun J, Radeke MJ, Feinstein SC, Miller JA (1994): Distribution of intracerebral ventricularly administered neurotrophins in rat brain and its correlation with trk receptor expression. Exp Neurol. 127: 23-36.

29. Caleo M, Cenni MC (2004): Anterograde transport of neurotrophic factors. Mol Neurobiol. 29: $179-195$.

30. Conner JM, Lauterborn JC, Yan Q, Gall CM, Varon S (1997): Distribution of brain-derived neurotrophic factor (BDNF) protein and mRNA in the normal adult rat CNS: evidence for anterograde axonal transport. J Neurosci Off J Soc Neurosci. 17: 2295-2313.

31. DiStefano PS, Friedman B, Radziejewski C, Alexander C, Boland P, Schick CM, et al. (1992): The neurotrophins BDNF, NT-3, and NGF display distinct patterns of retrograde axonal transport in peripheral and central neurons. Neuron. 8: 983-993.

32. Guo L, Yeh ML, Cuzon Carlson VC, Johnson-Venkatesh EM, Yeh HH (2012): Nerve growth factor in the hippocamposeptal system: Evidence for activity-dependent anterograde delivery and modulation of synaptic activity. J Neurosci. 32: 7701-7710.

33. Biane J, Conner JM, Tuszynski MH (2014): Nerve growth factor is primarily produced by GABAergic neurons of the adult rat cortex. Front Cell Neurosci. 8: 220.

34. Zhang H-T, Li L-Y, Zou X-L, Song X-B, Hu Y-L, Feng Z-T, Wang TT-H (2007): Immunohistochemical Distribution of NGF, BDNF, NT-3, and NT-4 in Adult Rhesus Monkey Brains. J Histochem Cytochem. 55: 1-19.

35. Pan Z, Perez-Polo R (1993): Role of Nerve Growth Factor in Oxidanl Homeostasis: Glutathione Metabolism. J Neurochem. 61: 1713-1721.

36. Sivilia S, Paradisi M, D’Intino G, Fernandez M, Pirondi S, Lorenzini L, Calza L (2008): Skin homeostasis during inflammation, a role for nerve growth factor. . 
37. Barbosa IG, Huguet RB, Neves FS, Reis HJ, Bauer ME, Janka Z, et al. (2011): Impaired nerve growth factor homeostasis in patients with bipolar disorder. World J Biol Psychiatry. 12: 228232.

38. Castrén E, Rantamäki T (2008): Neurotrophins in depression and antidepressant effects. Novartis Found Symp. 289: 43-52; discussion 53-59, 87-93.

39. Miranda RC, Sohrabji F, Toran-Allerand CD (1993): Neuronal colocalization of mRNAs for neurotrophins and their receptors in the developing central nervous system suggests a potential for autocrine interactions. Proc Natl Acad Sci U S A. 90: 6439-6443.

40. Baeza-Raja B, Eckel-Mahan K, Zhang L, Vagena E, Tsigelny IF, Sassone-Corsi P, et al. (2013): p75 neurotrophin receptor is a clock gene that regulates oscillatory components of circadian and metabolic networks. J Neurosci Off J Soc Neurosci. 33: 10221-10234.

41. Liang F-Q, Allen G, Earnest D (2000): Role of brain-derived neurotrophic factor in the circadian regulation of the suprachiasmatic pacemaker by light. J Neurosci. 20: 2978-2987.

42. Naert G, Ixart G, Maurice T, Tapia-Arancibia L, Givalois L (2011): Brain-derived neurotrophic factor and hypothalamic-pituitary-adrenal axis adaptation processes in a depressive-like state induced by chronic restraint stress. Mol Cell Neurosci. 46: 55-66.

43. Tyler WJ, Perrett SP, Pozzo-Miller LD (2002): The Role of Neurotrophins in Neurotransmitter Release. Neurosci Rev J Bringing Neurobiol Neurol Psychiatry. 8: 524-531.

44. Huber R, Tononi G, Cirelli C (2007): Exploratory behavior, cortical BDNF expression, and sleep homeostasis. Sleep. 30: 129-139.

45. Matsuda N, Lu H, Fukata Y, Noritake J, Gao H, Mukherjee S, et al. (2009): Differential ActivityDependent Secretion of Brain-Derived Neurotrophic Factor from Axon and Dendrite. $J$ Neurosci. 29: 14185-14198.

46. Neeper SA, Góauctemez-Pinilla F, Choi J, Cotman C (1995): Exercise and brain neurotrophins. Nature. 373: 109-109.

47. Pardon M-C (2010): Role of neurotrophic factors in behavioral processes: implications for the treatment of psychiatric and neurodegenerative disorders. Vitam Horm. 82: 185-200.

48. Vigers AJ, Amin DS, Talley-Farnham T, Gorski JA, Xu B, Jones KR (2012): Sustained expression of brain-derived neurotrophic factor is required for maintenance of dendritic spines and normal behavior. Neuroscience. 212: 1-18.

49. Carmignoto G, Pizzorusso T, Tia S, Vicini S (1997): Brain-derived neurotrophic factor and nerve growth factor potentiate excitatory synaptic transmission in the rat visual cortex. $J$ Physiol. 498: 153-164.

50. De Rosa R, Garcia AA, Braschi C, Capsoni S, Maffei L, Berardi N, Cattaneo A (2005): Intranasal administration of nerve growth factor (NGF) rescues recognition memory deficits in AD11 anti-NGF transgenic mice. Proc Natl Acad Sci U S A. 102: 3811-3816. 
51. Fischer W, Bjorklund A, Chen K, Gage F (1991): NGF improves spatial memory in aged rodents as a function of age. J Neurosci. 11: 1889-1906.

52. Tyler WJ, Alonso M, Bramham CR, Pozzo-Miller LD (2002): From Acquisition to Consolidation: On the Role of Brain-Derived Neurotrophic Factor Signaling in Hippocampal-Dependent Learning. Learn Mem. 9: 224-237.

53. Faraguna U, Vyazovskiy VV, Nelson AB, Tononi G, Cirelli C (2008): A causal role for brainderived neurotrophic factor in the homeostatic regulation of sleep. $J$ Neurosci. 28: 40884095 .

54. Ramos OV, Torterolo P, Lim V, Chase MH, Sampogna S, Yamuy J (2011): The role of mesopontine NGF in sleep and wakefulness. Brain Res. 1413: 9-23.

55. Takahashi S, Krueger JM (1999): Nerve growth factor enhances sleep in rabbits. Neurosci Lett. 264: $149-152$.

56. Cheng B, Mattson MP (1994): NT-3 and BDNF protect CNS neurons against metabolic/excitotoxic insults. Brain Res. 640: 56-67.

57. Taylor SL, Stanek LM, Ressler KJ, Huhman KL (2011): Differential brain-derived neurotrophic factor expression in limbic brain regions following social defeat or territorial aggression. Behav Neurosci. 125: 911-920.

58. Lester KJ, Hudson JL, Tropeano M, Creswell C, Collier DA, Farmer A, et al. (2012): Neurotrophic gene polymorphisms and response to psychological therapy. Transl Psychiatry. 2: e108.

59. Lang UE, Hellweg R, Gallinat J (2004): BDNF serum concentrations in healthy volunteers are associated with depression-related personality traits. Neuropsychopharmacol Off Publ Am Coll Neuropsychopharmacol. 29: 795-798.

60. Egan MF, Kojima M, Callicott JH, Goldberg TE, Kolachana BS, Bertolino A, et al. (2003): The BDNF val66met polymorphism affects activity-dependent secretion of BDNF and human memory and hippocampal function. Cell. 112: 257-269.

61. Colzato LS, Van der Does AJW, Kouwenhoven C, Elzinga BM, Hommel B (2011): BDNF Val66Met polymorphism is associated with higher anticipatory cortisol stress response, anxiety, and alcohol consumption in healthy adults. Psychoneuroendocrinology. 36: 15621569.

62. Shalev I, Lerer E, Israel S, Uzefovsky F, Gritsenko I, Mankuta D, et al. (2009): BDNF Val66Met polymorphism is associated with HPA axis reactivity to psychological stress characterized by genotype and gender interactions. Psychoneuroendocrinology. 34: 382-388.

63. Tsuru J, Tanaka Y, Ishitobi Y, Maruyama Y, Inoue A, Kawano A, et al. (2014): Association of BDNF Val66Met polymorphism with HPA and SAM axis reactivity to psychological and physical stress. Neuropsychiatr Dis Treat. 10: 2123-2133.

64. Alleva E, Branchi I (2006): NGF: a social molecule. Psychoneuroendocrinology. 31: 295-296. 
65. Branchi I, Francia N, Alleva E (2004): Epigenetic control of neurobehavioural plasticity: the role of neurotrophins. Behav Pharmacol. 15: 353-362.

66. Levine S (2001): Primary social relationships influence the development of the hypothalamicpituitary-adrenal axis in the rat. Physiol Behav. 73: 255-260.

67. Ratto MH, Leduc YA, Valderrama XP, van Straaten KE, Delbaere LT, Pierson RA, Adams GP (2012): The nerve of ovulation-inducing factor in semen. Proc Natl Acad Sci. 109: 1504215047.

68. Emanuele E, Politi P, Bianchi M, Minoretti P, Bertona M, Geroldi D (2006): Raised plasma nerve growth factor levels associated with early-stage romantic love. Psychoneuroendocrinology. 31: $288-294$.

69. Alvarez-Buylla A, García-Verdugo JM (2002): Neurogenesis in adult subventricular zone. $J$ Neurosci. 22: 629-634.

70. Eriksson PS, Perfilieva E, Björk-Eriksson T, Alborn A-M, Nordborg C, Peterson DA, Gage FH (1998): Neurogenesis in the adult human hippocampus. Nat Med. 4: 1313-1317.

71. Levone BR, Cryan JF, O’Leary OF (2015): Role of adult hippocampal neurogenesis in stress resilience. Neurobiol Stress, Stress Resilience. 1: 147-155.

72. Opendak M, Gould E (2015): Adult neurogenesis: a substrate for experience-dependent change. Trends Cogn Sci. 19: 151-161.

73. Kang E, Wen Z, Song H, Christian KM, Ming G (2016): Adult Neurogenesis and Psychiatric Disorders. Cold Spring Harb Perspect Biol. a019026.

74. Küppers E, Beyer C (2001): Dopamine regulates brain-derived neurotrophic factor (BDNF) expression in cultured embryonic mouse striatal cells. Neuroreport. 12: 1175-1179.

75. Paredes D, Granholm A-C, Bickford PC (2007): Effects of NGF and BDNF on baseline glutamate and dopamine release in the hippocampal formation of the adult rat. Brain Res. 1141: 56-64.

76. Esch T, Stefano GB (2004): The neurobiology of pleasure, reward processes, addiction and their health implications. Neuro Endocrinol Lett. 25: 235-251.

77. Berton O, McClung CA, Dileone RJ, Krishnan V, Renthal W, Russo SJ, et al. (2006): Essential role of BDNF in the mesolimbic dopamine pathway in social defeat stress. Science. 311: 864868.

78. Walsh JJ, Friedman AK, Sun H, Heller EA, Ku SM, Juarez B, et al. (2014): Stress and CRF gate neural activation of BDNF in the mesolimbic reward pathway. Nat Neurosci. 17: 27-29.

79. Barco A, Jancic D, Kandel ER (2008): CREB-Dependent Transcription and Synaptic Plasticity. In: Dudek SM, editor. Transcr Regul Neuronal Act. Springer US, pp 127-154.

80. Finkbeiner S, Tavazoie SF, Maloratsky A, Jacobs KM, Harris KM, Greenberg ME (1997): CREB: a major mediator of neuronal neurotrophin responses. Neuron. 19: 1031-1047. 
81. Middei S, Spalloni A, Longone P, Pittenger C, O’Mara SM, Marie H, Ammassari-Teule M (2012): CREB selectively controls learning-induced structural remodeling of neurons. Learn Mem. 19: 330-336.

82. Bersani G, Iannitelli A, Maselli P, Pancheri P, Aloe L, Angelucci F, Alleva E (1999): Low nerve growth factor plasma levels in schizophrenic patients: a preliminary study. Schizophr Res. 37: 201.

83. Gioiosa L, Iannitelli A, Aloe L (2009): Stress, anxiety schizophrenia and neurotrophic factors: the pioneer studies with nerve growth factor. Riv Psichiatr. 44: 88-94.

84. Takahashi M, Shirakawa O, Toyooka K, Kitamura N, Hashimoto T, Maeda K, et al. (2000): Abnormal expression of brain-derived neurotrophic factor and its receptor in the corticolimbic system of schizophrenic patients. Mol Psychiatry. 5: 293-300.

85. Liu X, Zhang T, He S, Hong B, Chen Z, Peng D, et al. (2014): Elevated serum levels of FGF-2, NGF and IGF-1 in patients with manic episode of bipolar disorder. Psychiatry Res. 218: 5460.

86. Angelucci F, Aloe L, Jiménez-Vasquez P, Mathé AA (2003): Lithium treatment alters brain concentrations of nerve growth factor, brain-derived neurotrophic factor and glial cell linederived neurotrophic factor in a rat model of depression. Int J Neuropsychopharmacol. 6: $225-231$.

87. Martino M, Rocchi G, Escelsior A, Contini P, Colicchio S, de Berardis D, et al. (2013): NGF serum levels variations in major depressed patients receiving duloxetine. Psychoneuroendocrinology. 38: 1824-1828.

88. Fontenelle LF, Barbosa IG, Luna JV, Rocha NP, Silva Miranda A, Teixeira AL (2012): Neurotrophic factors in obsessive-compulsive disorder. Psychiatry Res. 199: 195-200.

89. Hemmings DSMJ, Kinnear CJ, Merwe LVD, Lochner C, Corfield VA, Moolman-Smook JC, Stein DJ (2008): Investigating the role of the brain-derived neurotrophic factor (BDNF) val66met variant in obsessive-compulsive disorder (OCD). World J Biol Psychiatry. 9: 126134.

90. Wang Y, Mathews CA, Li Y, Lin Z, Xiao Z (2011): Brain-derived neurotrophic factor (BDNF) plasma levels in drug-naïve OCD patients are lower than those in healthy people, but are not lower than those in drug-treated OCD patients. J Affect Disord. 133: 305-310.

91. Andero R, Ressler KJ (2012): Fear extinction and BDNF: Translating animal models of PTSD to the clinic. Genes Brain Behav. 11: 503-512.

92. Green CR, Corsi-Travali S, Neumeister A (2013): The role of BDNF-TrkB signaling in the pathogenesis of PTSD. J Depress Anxiety. 2013.

93. Hashimoto K, Koizumi H, Nakazato M, Shimizu E, Iyo M (2005): Role of brain-derived neurotrophic factor in eating disorders: recent findings and its pathophysiological implications. Prog Neuropsychopharmacol Biol Psychiatry. 29: 499-504. 
94. Deveci A, Aydemir O, Taskin O, Taneli F, Esen-Danaci A (2007): Serum brain-derived neurotrophic factor levels in conversion disorder: Comparative study with depression. Psychiatry Clin Neurosci. 61: 571-573.

95. Aloe L, Alleva E, De Simone R (1990): Changes of NGF level in mouse hypothalamus following intermale aggressive behaviour: biological and immunohistochemical evidence. Behav Brain Res. 39: 53-61.

96. Dwivedi Y (2010): Brain-derived neurotrophic factor and suicide pathogenesis. Ann Med. 42: 8796.

97. Dwivedi Y, Mondal AC, Rizavi HS, Conley RR (2005): Suicide brain is associated with decreased expression of neurotrophins. Biol Psychiatry. 58: 315-324.

98. Pregelj P, Nedic G, Paska AV, Zupanc T, Nikolac M, Balažic J, et al. (2011): The association between brain-derived neurotrophic factor polymorphism (BDNF Val66Met) and suicide. $J$ Affect Disord. 128: 287-290.

99. Bie B, Wang Y, Cai Y-Q, Zhang Z, Hou Y-Y, Pan ZZ (2012): Upregulation of nerve growth factor in central amygdala increases sensitivity to opioid reward. Neuropsychopharmacology. 37: $2780-2788$.

100. Heberlein A, Muschler M, Frieling H, Behr M, Eberlein C, Wilhelm J, et al. (2013): Epigenetic down regulation of nerve growth factor during alcohol withdrawal. Addict Biol. 18: 508-510.

101. Jockers-ScherüB1 MC, Matthies U, Danker-Hopfe H, Lang UE, Mahlberg R, Hellweg R (2003): Chronic cannabis abuse raises nerve growth factor serum concentrations in drug-naive schizophrenic patients. $J$ Psychopharmacol (Oxf). 17: 439-445.

102. Jockers-Scherübl MC, Rentzsch J, Danker-Hopfe H, Radzei N, Schürer F, Bahri S, Hellweg R (2006): Adequate antipsychotic treatment normalizes serum nerve growth factor concentrations in schizophrenia with and without cannabis or additional substance abuse. Neurosci Lett. 400: 262-266.

103. Cirulli F, Alleva E (2009): The NGF saga: from animal models of psychosocial stress to stressrelated psychopathology. Front Neuroendocrinol. 30: 379-395.

104. Boulle F, van den Hove DLA, Jakob SB, Rutten BP, Hamon M, van Os J, et al. (2012): Epigenetic regulation of the BDNF gene: implications for psychiatric disorders. Mol Psychiatry. 17: 584-596.

105. Castrén E (2014): Neurotrophins and psychiatric disorders. Neurotrophic Factors. Springer, pp $461-479$.

106. McEwen BS (2004): Protection and damage from acute and chronic stress: allostasis and allostatic overload and relevance to the pathophysiology of psychiatric disorders. Ann N Y Acad Sci. 1032: 1-7.

107. Kumar A, Pareek V, Faiq MA, Kumar P, Raza K, Prasoon P, et al. (2017): Regulatory role of NGFs in neurocognitive functions. Rev Neurosci. 0. doi: 10.1515/revneuro-2016-0031. 
108. Smith MA, Makino S, Kvetnansky R, Post RM (1995): Stress and glucocorticoids affect the expression of brain-derived neurotrophic factor and neurotrophin-3 mRNAs in the hippocampus. J Neurosci Off J Soc Neurosci. 15: 1768-1777.

109. Taliaz D, Loya A, Gersner R, Haramati S, Chen A, Zangen A (2011): Resilience to Chronic Stress Is Mediated by Hippocampal Brain-Derived Neurotrophic Factor. J Neurosci. 31: 4475-4483.

110. Foreman PJ, Taglialatela G, Angelucci L, Turner CP, Perez-Polo JR (1993): Nerve growth factor and p75NGFR factor receptor mRNA change in rodent CNS following stress activation of the hypothalamo-pituitary-adrenocortical axis. J Neurosci Res. 36: 10-18.

111. Li S, Wang C, Wang W, Dong H, Hou P, Tang Y (2008): Chronic mild stress impairs cognition in mice: from brain homeostasis to behavior. Life Sci. 82: 934-942.

112. Taglialatela G, Angelucci L, Scaccianoce S, Foreman P, Perez-Polo J (1991): Nerve growth factor modulates the activation of the hypothalamo-pituitary-adrenocortical axis during the stress response. Endocrinology. 129: 2212-2218.

113. Autry AE, Monteggia LM (2012): Brain-Derived Neurotrophic Factor and Neuropsychiatric Disorders. Pharmacol Rev. 64: 238-258.

114. Jeanneteau FD, Lambert WM, Ismaili N, Bath KG, Lee FS, Garabedian MJ, Chao MV (2012): BDNF and glucocorticoids regulate corticotrophin-releasing hormone (CRH) homeostasis in the hypothalamus. Proc Natl Acad Sci. 109: 1305-1310.

115. Herman JP, Cullinan WE (1997): Neurocircuitry of stress: central control of the hypothalamopituitary-adrenocortical axis. Trends Neurosci. 20: 78-84.

116. Lakshminarasimhan H, Chattarji S (2012): Stress Leads to Contrasting Effects on the Levels of Brain Derived Neurotrophic Factor in the Hippocampus and Amygdala. PLOS ONE. 7: e30481.

117. Baumeister D, Lightman SL, Pariante CM (2014): The Interface of Stress and the HPA Axis in Behavioural Phenotypes of Mental Illness. Curr Top Behav Neurosci. 18: 13-24.

118. McEwen BS (1999): Stress and Hippocampal Plasticity. Annu Rev Neurosci. 22: 105-122.

119. Sapolsky RM, Uno H, Rebert CS, Finch CE (1990): Hippocampal damage associated with prolonged glucocorticoid exposure in primates. J Neurosci Off J Soc Neurosci. 10: 28972902.

120. Watanabe Y, Gould E, McEwen BS (1992): Stress induces atrophy of apical dendrites of hippocampal CA3 pyramidal neurons. Brain Res. 588: 341-345.

121. Herman JP, Ostrander MM, Mueller NK, Figueiredo H (2005): Limbic system mechanisms of stress regulation: hypothalamo-pituitary-adrenocortical axis. Prog Neuropsychopharmacol Biol Psychiatry. 29: 1201-1213.

122. Daskalakis NP, De Kloet ER, Yehuda R, Malaspina D, Kranz TM (2015): Early Life Stress Effects on Glucocorticoid-BDNF Interplay in the Hippocampus. Front Mol Neurosci. 68. 
123. Cirulli F, Micera A, Alleva E, Aloe L (1998): Early maternal separation increases NGF expression in the developing rat hippocampus. Pharmacol Biochem Behav. 59: 853-858.

124. Shi S-S, Shao S, Yuan B, Pan F, Li Z-L (2010): Acute Stress and Chronic Stress Change BrainDerived Neurotrophic Factor (BDNF) and Tyrosine Kinase-Coupled Receptor (TrkB) Expression in Both Young and Aged Rat Hippocampus. Yonsei Med J. 51: 661-671.

125. Lambert WM, Xu C-F, Neubert TA, Chao MV, Garabedian MJ, Jeanneteau FD (2013): BrainDerived Neurotrophic Factor Signaling Rewrites the Glucocorticoid Transcriptome via Glucocorticoid Receptor Phosphorylation. Mol Cell Biol. 33: 3700-3714.

126. Turecki G (2014): The molecular bases of the suicidal brain. Nat Rev Neurosci. 15: 802-816.

127. Givalois L, Naert G, Rage F, Ixart G, Arancibia S, Tapia-Arancibia L (2004): A single brainderived neurotrophic factor injection modifies hypothalamo-pituitary-adrenocortical axis activity in adult male rats. Mol Cell Neurosci. 27: 280-295.

128. Naert G, Ixart G, Tapia-Arancibia L, Givalois L (2006): Continuous i.c.v. infusion of brainderived neurotrophic factor modifies hypothalamic-pituitary-adrenal axis activity, locomotor activity and body temperature rhythms in adult male rats. Neuroscience. 139: 779-789.

129. Naert G, Zussy C, Tran Van Ba C, Chevallier N, Tang Y-P, Maurice T, Givalois L (2015): Involvement of Endogenous Brain-Derived Neurotrophic Factor in Hypothalamic-PituitaryAdrenal Axis Activity. J Neuroendocrinol. 27: 850-860.

130. Roth TL, Lubin FD, Funk AJ, Sweatt JD (2009): Lasting epigenetic influence of early-life adversity on the BDNF gene. Biol Psychiatry. 65: 760-769.

131. Roth TL, Zoladz PR, Sweatt JD, Diamond DM (2011): Epigenetic modification of hippocampal Bdnf DNA in adult rats in an animal model of post-traumatic stress disorder. $J$ Psychiatr Res. 45: 919-926.

132. Bird A (2007): Perceptions of epigenetics. Nature. 447: 396-398.

133. Champagne FA (2013): Early environments, glucocorticoid receptors, and behavioral epigenetics. Behav Neurosci. 127: 628-636.

134. Champagne FA, Curley JP (2009): Epigenetic mechanisms mediating the long-term effects of maternal care on development. Neurosci Biobehav Rev. 33: 593-600.

135. Weaver ICG, Cervoni N, Champagne FA, D'Alessio AC, Sharma S, Seckl JR, et al. (2004): Epigenetic programming by maternal behavior. Nat Neurosci. 7: 847-854.

136. Weaver ICG, Champagne FA, Brown SE, Dymov S, Sharma S, Meaney MJ, Szyf M (2005): Reversal of maternal programming of stress responses in adult offspring through methyl supplementation: altering epigenetic marking later in life. J Neurosci Off J Soc Neurosci. 25: 11045-11054.

137. Francis DD, Diorio J, Plotsky PM, Meaney MJ (2002): Environmental enrichment reverses the effects of maternal separation on stress reactivity. J Neurosci. 22: 7840-7843. 
138. Jawahar MC, Murgatroyd C, Harrison EL, Baune BT (2015): Epigenetic alterations following early postnatal stress: a review on novel aetiological mechanisms of common psychiatric disorders. Clin Epigenetics. 7: 122.

139. Wu Y, Patchev AV, Daniel G, Almeida OFX, Spengler D (2014): Early-life stress reduces DNA methylation of the Pomc gene in male mice. Endocrinology. 155: 1751-1762.

140. Murgatroyd C, Patchev AV, Wu Y, Micale V, Bockmühl Y, Fischer D, et al. (2009): Dynamic DNA methylation programs persistent adverse effects of early-life stress. Nat Neurosci. 12: 1559-1566.

141. Bowen MT, Dass SAH, Booth J, Suraev A, Vyas A, McGregor IS (2014): Active coping toward predatory stress is associated with lower corticosterone and progesterone plasma levels and decreased methylation in the medial amygdala vasopressin system. Horm Behav. 66: 561566.

142. Aloe L, Alleva E, Fiore M (2002): Stress and nerve growth factor: findings in animal models and humans. Pharmacol Biochem Behav. 73: 159-166.

143. McGowan PO, Sasaki A, D’Alessio AC, Dymov S, Labonté B, Szyf M, et al. (2009): Epigenetic regulation of the glucocorticoid receptor in human brain associates with childhood abuse. Nat Neurosci. 12: 342-348.

144. Marco EM, Llorente R, López-Gallardo M, Mela V, Llorente-Berzal Á, Prada C, Viveros M-P (2015): The maternal deprivation animal model revisited. Neurosci Biobehav Rev. 51: 151163.

145. Chen WG, Chang Q, Lin Y, Meissner A, West AE, Griffith EC, et al. (2003): Derepression of BDNF transcription involves calcium-dependent phosphorylation of MeCP2. Science. 302: 885-889.

146. Rage F, Givalois L, Marmigère F, Tapia-Arancibia L, Arancibia S (2002): Immobilization stress rapidly modulates BDNF mRNA expression in the hypothalamus of adult male rats. Neuroscience. 112: 309-318.

147. Unternaehrer E, Luers P, Mill J, Dempster E, Meyer AH, Staehli S, et al. (2012): Dynamic changes in DNA methylation of stress-associated genes (OXTR, BDNF) after acute psychosocial stress. Transl Psychiatry. 2: e150.

148. Weaver ICG, D’Alessio AC, Brown SE, Hellstrom IC, Dymov S, Sharma S, et al. (2007): The transcription factor nerve growth factor-inducible protein a mediates epigenetic programming: altering epigenetic marks by immediate-early genes. J Neurosci Off $J$ Soc Neurosci. 27: $1756-1768$.

149. Hu Y, Russek SJ (2008): BDNF and the diseased nervous system: a delicate balance between adaptive and pathological processes of gene regulation. J Neurochem. 105: 1-17.

150. Hamshere ML, Walters JTR, Smith R, Richards AL, Green E, Grozeva D, et al. (2013): Genome-wide significant associations in schizophrenia to ITIH3/4, CACNA1C and 
SDCCAG8, and extensive replication of associations reported by the Schizophrenia PGC. Mol Psychiatry. 18: 708-712.

151. Ninan I (2014): Synaptic regulation of affective behaviors; role of BDNF. Neuropharmacology. 76. doi: 10.1016/j.neuropharm.2013.04.011. 